\title{
Triple Band Planar Antenna for Wireless Communication
}

\author{
Priyanarayan Misra \\ E.A.S.T. \\ Bhubaneswar \\ India
}

\author{
Amaresh Tripathy \\ E.A.S.T. \\ Bhubaneswar \\ India
}

\begin{abstract}
This paper presents a triple band planar antenna for wireless communication. The antenna is printed on FR4 substrate. The patch shape and the ground plane are studied to achieve the desired bandwidth. The reconfiguration of antenna is studied to improve the performance of antenna in terms of the return loss behavior. The designed antenna structure is simulated using CST Microwave studio. The simulation results in terms of return loss are studied. The antenna satisfies triple band operation with good radiation characteristics.
\end{abstract}

\section{Keywords}

Monopole antenna, patch, reconfiguration, slot

\section{INTRODUCTION}

Planar antennas have been largely used in a lot of useful applications, because of their inherent characteristics of low cost, low profile, ease of fabrication, light, weight, conformability and integration with RF devices. A monopole antenna is a variation of half-wavelength dipole. When one of the half-wavelength conductor is replaced by a big "enough" conducting plane (also known as ground plane), the whole thing become a monopole antenna. Current flow inside conductor can induce an image current flowing in the ground plane, where this ground plane acts as the second halfwavelength conductor. Therefore the whole thing can act like a half-wave dipole. Moreover, ground plane size is important to monopole antenna because it requires a quarter-wavelength of current flowing path is formed in it to guarantee the antenna is functioning properly. Recently many antennas with multiband and wideband characteristics have been successfully designed for wireless applications [1]-[5]. In these designs, they can provide a dual-band operation for the application in the wireless local area network (WLAN) communication systems. In this paper, a new monopole multiband antenna is proposed which supports triple band operations at $2.45 \mathrm{GHz}, 5.15 \mathrm{GHz}$, and $7.3 \mathrm{GHz}$ with good bandwidth.

\section{ANTENNA GEOMETRY}

Fig 1 shows the geometry and dimensions of the initial planar monopole antenna for multiband operation. The proposed antenna is excited using a 50- microstrip feed line of width 3 $\mathrm{mm}$. The FR4 substrate $\left(\varepsilon_{\gamma}=4.5\right)$ covers total area of $24 \times 48 \times$ $1.6 \mathrm{~mm}$. The radiating element is chosen with a dimension of $14 \times 26 \mathrm{~mm}$ which is further reconfigured. The ground plane is selected to be $24 \times 9 \mathrm{~mm}$ and is printed on the back of the substrate.
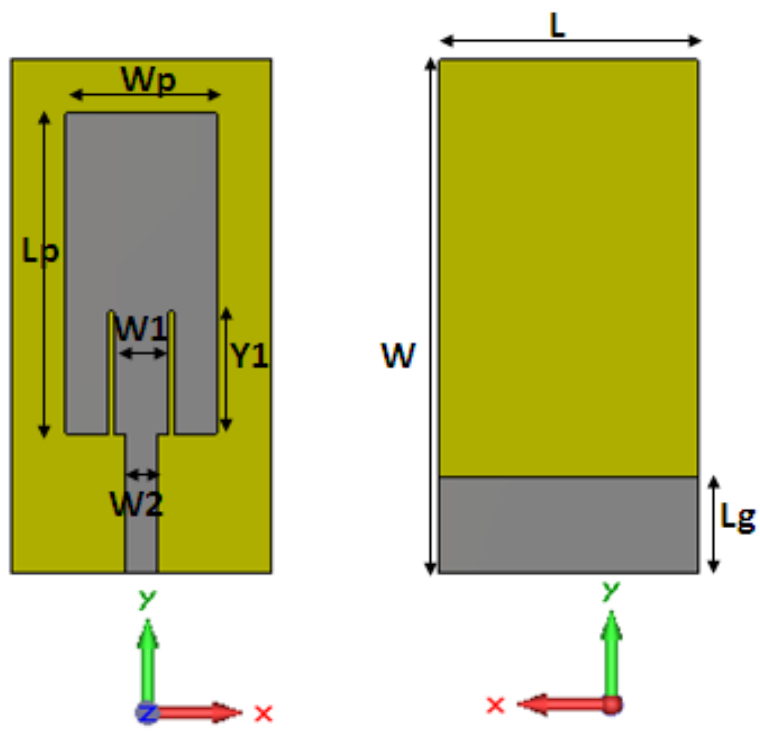

Fig 1: Antenna Geometry

$(\mathrm{Lp}=26 \mathrm{~mm}, \mathrm{Wp}=10 \mathrm{~mm}, \mathrm{~W} 1=5 \mathrm{~mm}, \mathrm{~W} 2=3 \mathrm{~mm}, \mathrm{Y} 1=\mathrm{mm}$, $\mathrm{L}=24 \mathrm{~mm}, \mathrm{~W}=48 \mathrm{~mm}, \mathrm{Lg}=\mathrm{mm}$ )

The designed antenna is simulated and the simulated result in terms of return loss plot is shown in figure 2.

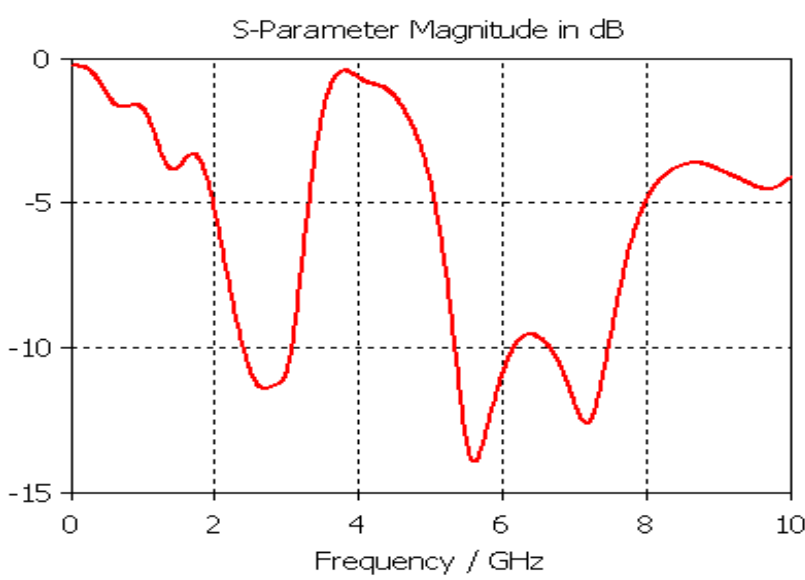

Fig 1: Simulated Return Loss

The return loss plot shows the triple band operation of the designed antenna. The antenna exhibits bandwidth at 2.4-3 $\mathrm{GHz}, 5.34-6.1 \mathrm{GHz}$ and $6.7-7.47 \mathrm{GHz}$ respectively.

\section{MODIFICATION OF ANTENNA STRUCTURE}

The next effort in this is to reconfigure the design and to improve the return loss the proposed reconfigured antenna consists of a $\mathrm{T}$ shaped radiator with two L- shaped stubs. The 
ground plane is fixed with a narrow vertical slot along the length of its center.
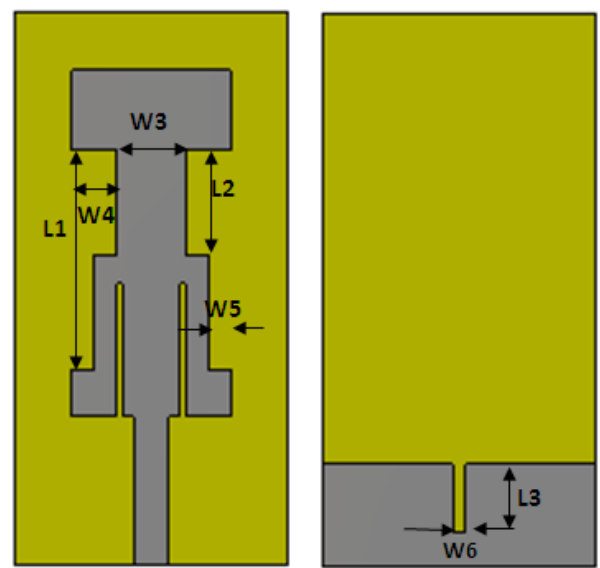

Fig 3: Modified Antenna Geometry

$(\mathrm{L} 1=19 \mathrm{~mm}, \mathrm{~L} 2=9 \mathrm{~mm}, \mathrm{~L} 3=6 \mathrm{~mm}, \mathrm{~W} 3=6 \mathrm{~mm}, \mathrm{~W} 4=4 \mathrm{~mm}$, $\mathrm{W} 5=2 \mathrm{~mm}, \mathrm{~W} 6=1 \mathrm{~mm}$ )

The reconfigured antenna is simulated and the result in terms of return loss plot and VSWR is shown in figure 4 and 5

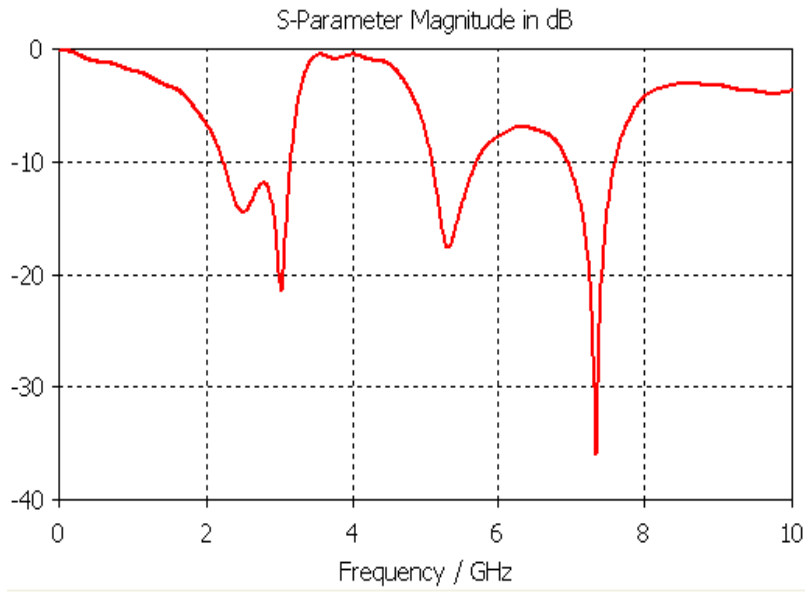

Fig 4: Simulated Return Loss

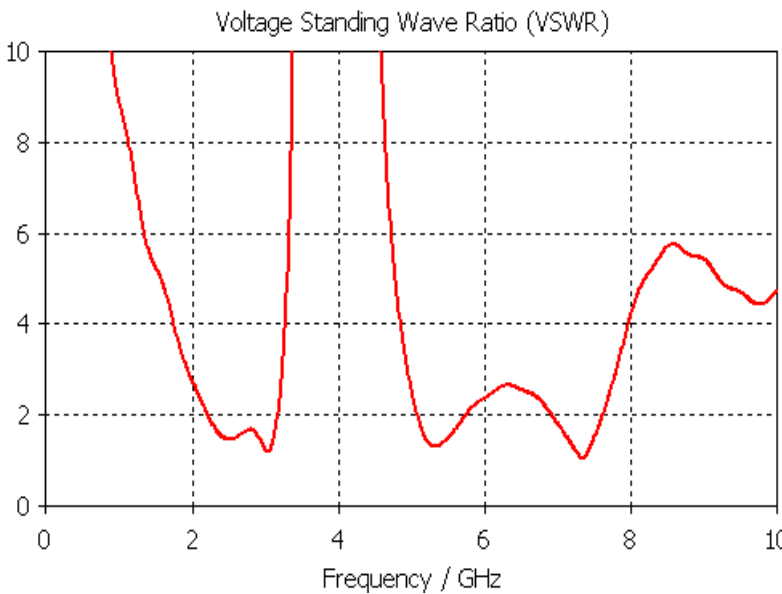

Fig 5: Simulated VSWR plot

The return loss plot of the reconfigured antenna is improved than the main antenna. The new reconfigured structure shows more negative return loss as compared to the main antenna. The bandwidth of the new shape obtained from the return loss and VSWR curve is $2.21-3.15 \mathrm{GHz}, 5.08-5.72 \mathrm{GHz}$ and $6.92-$ $7.58 \mathrm{GHz}$ respectively.

\section{CURRENT DISTRIBUTION}

The physical behavior of the antenna is studied from the surface current distribution pattern. The surface current distributions for the proposed reconfigured antenna at 2.45, 5.15 and $7.3 \mathrm{GHz}$ are studied which are shown in figure 6 .

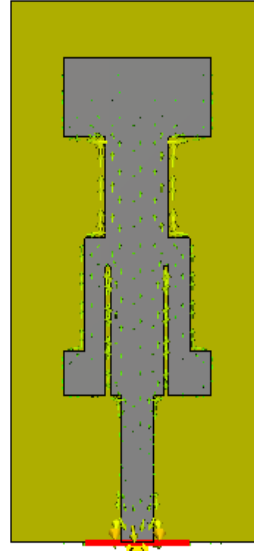

2. $45 \mathrm{GHz}$

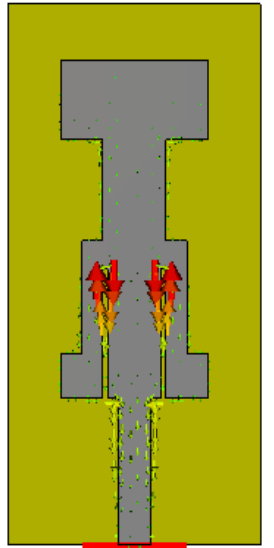

$5.15 \mathrm{GHz}$

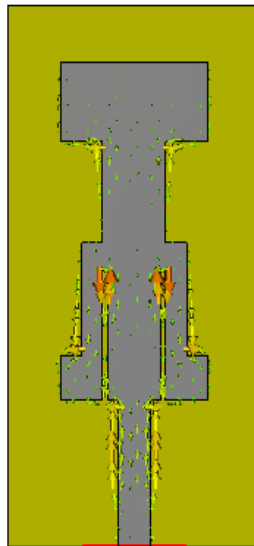

$7.3 \mathrm{GHz}$
Fig 6: Surface current distribution

51,1 The current distribution on the patch shows that the density is more at $2.45 \mathrm{GHz}$ towards the horizontal shape of T- shaped radiator and more near the two L- shaped stubs at 5.15 and 7.3 GHz. The T- Shaped radiator provides the lower mode covering the lower band, while the addition of two L- shaped stubs provide the higher band.

\section{RADIATION PATTERN}

The far field radiation patterns in terms of 3D view and polar plot for the proposed antenna are shown in figure 7 and 8 at frequencies $2.45,5.15$ and $7.3 \mathrm{GHz}$ respectively. The antenna having gains $2.54,3.613$ and $3.863 \mathrm{~dB}$ at frequencies 2.45, 5.15 and $7.3 \mathrm{GHz}$ respectively.

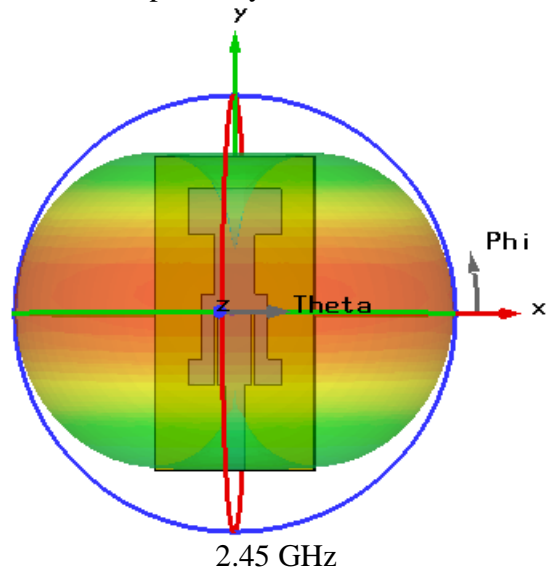




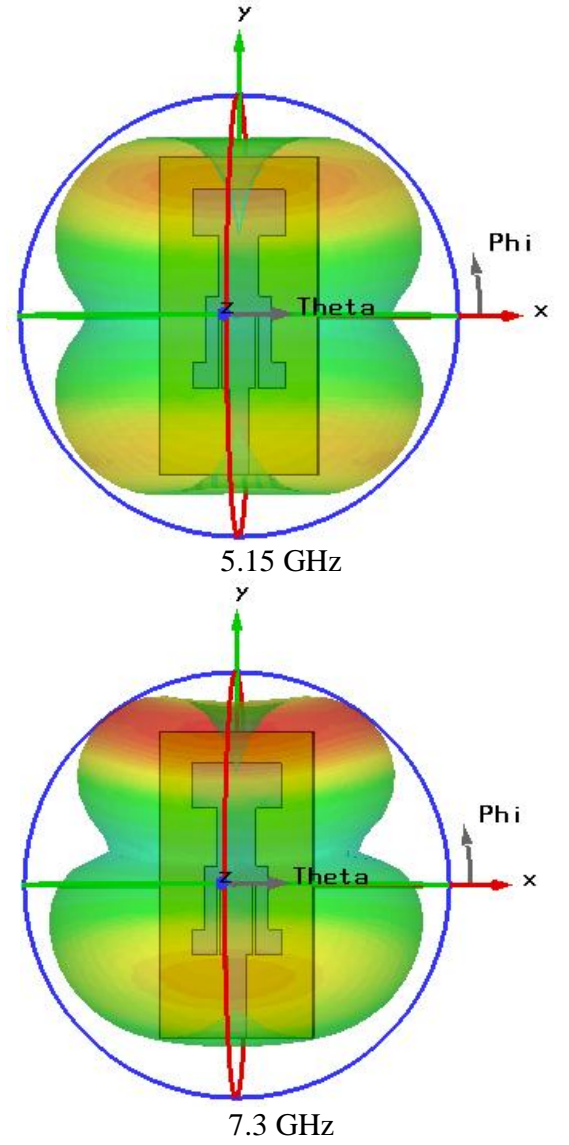

Fig 7: Radiation Patterns in terms of 3D View

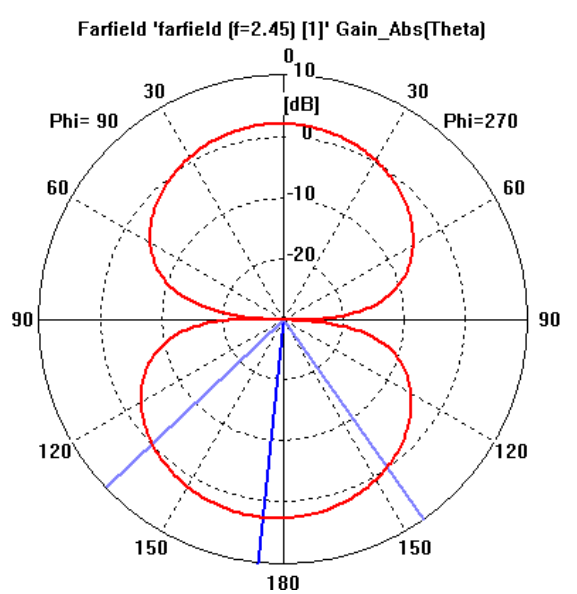

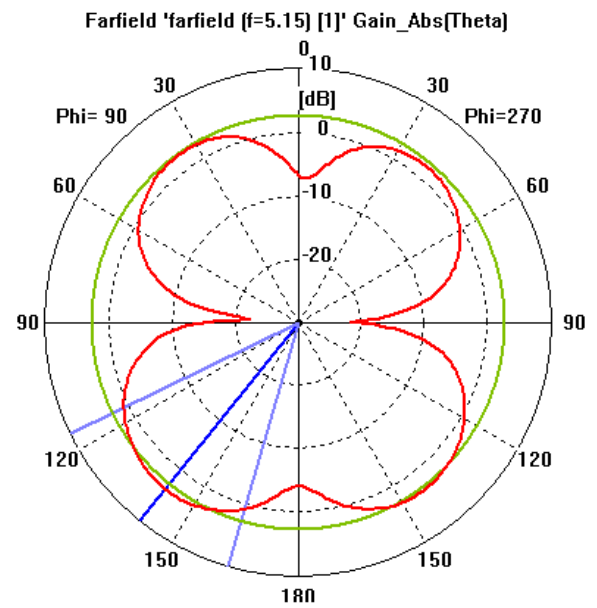

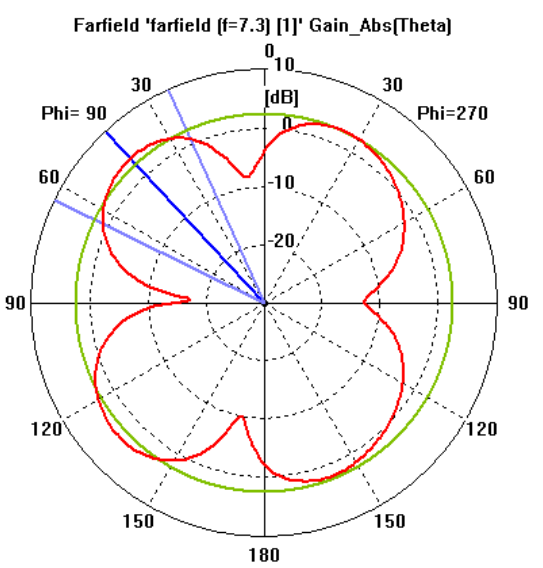

Fig 8: Radiation Patterns in terms of Polar Plot

\section{CONCLUSION}

The reconfigured antenna shows triple band operation with good return loss and bandwidth. The designed antenna can be suitable for different wireless applications like Bluetooth, WIMax, WI-Fi, and WLAN.

\section{REFERENCES}

[1] P. Ciais, R. Staraj, G. Kossiavas, and C. Luxey, "Compact internal multiband antenna for mobile phone and WLAN standards," Electron.Lett., vol. 40, pp. 920 921, Jul. 2004.

[2] H. C. Go and Y. W. Jang, "Multi-band modified forkshaped microstrip monopole antenna with ground plane including dual-triangle portion," Electron. Lett. vol. 40, pp. 575-577, May 2004.

[3] S. Y. Lin, "Multiband folded planar monopole antenna for mobile handset," IEEE Trans. Antennas Propag., vol. 52, no. 7, pp. 1790-1794, Jul. 2004.

[4] T. H. Kim and D. C. Park, "CPW-fed compact monopole antenna for dual-band WLAN applications," Electron. Lett., vol. 41, pp. 291-293, Mar. 2005

[5] H. D. Chen, J. S. Chen, and Y. T. Cheng, "Modified inverted-L monopole antenna for $2.4 / 5 \mathrm{GHz}$ dualband operations," Electron Lett, vol. 39, pp. 1567-1568, Oct. 2003 